\title{
Detection of p53 mutations in proliferating vascular cells in glioblastoma multiforme
}

\author{
Takuma Kawasoe, MD, ${ }^{1}$ Hideo Takeshima, MD, PhD, ${ }^{1}$ Shinji Yamashita, MD, ${ }^{1}$ \\ Sohei Mizuguchi, PhD, ${ }^{1}$ Tsuyoshi Fukushima, MD, PhD, ${ }^{2}$ Kiyotaka Yokogami, MD, PhD, ${ }^{1}$ \\ and Kouji Yamasaki, MD'
}

1Department of Neurosurgery, Division of Clinical Neuroscience, and 2Department of Oncopathology and Regenerative Biology, Division of Pathology, Faculty of Medicine, University of Miyazaki, Miyazaki, Japan

OBJECT Glioblastoma multiforme (GBM), one of the most aggressive tumors in humans, is highly angiogenic. However, treatment with the angiogenesis inhibitor bevacizumab has not significantly prolonged overall patient survival times. GBM resistance to angiogenesis inhibitors is attributed to multiple interacting mechanisms. Although mesenchymal transition via glioma stem-like cells has attracted attention, it is considered a poor biomarker. There is no simple method for differentiating tumor-derived and reactive vascular cells from normal cells. The authors attempted to detect the mesenchymal transition of tumor cells by means of p53 and isocitrate dehydrogenase 1 (IDH1) immunohistochemistry.

METHODS Using antibody against p53 and IDH1 R132H, the authors immunohistochemically analyzed GBM tissue from patients who had undergone surgery at the University of Miyazaki Hospital during August 2005-December 2011. They focused on microvascular proliferation with a p53-positive ratio exceeding 50\%. They compared TP53 mutations in original tumor tissues and in p53-positive and p53-negative microvascular proliferation cells collected by laser microdissection.

RESULTS Among 61 enrolled GBM patients, the first screening step (immunostaining) identified 46 GBMs as p53 positive, 3 of which manifested areas of prominent p53-positive microvascular proliferation ( $>50 \%$ ). Histologically, areas of p53-positive microvascular proliferation tended to be clustered, and they coexisted with areas of p53-negative microvascular proliferation. Both types of microvascular proliferation cells were clearly separated from original tumor cells by glial fibrillary acidic protein, epidermal growth factor receptor, and low-/high-molecular-weight cytokeratin. DNA sequencing analysis disclosed that p53-positive microvascular proliferation cells exhibited TP53 mutations identical to those observed in the original tumor; p53-negative microvascular proliferation cells contained a normal allele. Although immunostaining indicated that 3 ( 2 primary and 1 secondary) of the 61 GBMs were positive for IDH1, no tumors contained microvascular proliferation cells positive for IDH1 R132H.

CONCLUSIONS Some microvascular proliferation clusters in GBM result from mesenchymal transition. The identification of useful markers might reveal this phenomenon as an infrequent event in GBMs.

http://thejns.org/doi/abs/10.3171/2014.10.JNS132159

KEY WORDS glioblastoma; mesenchymal transition; p53; microvascular proliferation; laser microdissection; oncology

$\mathrm{G}$ LIOBLASTOMA multiforme (GBM), one of the most aggressive tumors in humans, is the most common malignant primary brain tumor in adults. It is highly angiogenic. Its most prominent histological characteristic is microvascular proliferation, identified by hyperproliferation and the piling of endothelial cells around vessel lumens, ${ }^{2,16}$ which contributes to the rapid growth of these tumors.

Among the cytokines involved in this process, vascular endothelial growth factor (VEGF) is highly expressed in patients with GBM. ${ }^{21}$ Because VEGF plays a pivotal role in promoting the growth and survival of blood vessels, ${ }^{10,17}$

ABBREVIATIONS GBM = glioblastoma multiforme; IDH1 = isocitrate dehydrogenase 1; PCR = polymerase chain reaction; VEGF = vascular endothelial growth factor. SUBMITTED October 16, 2013. ACCEPTED October 7, 2014.

INCLUDE WHEN CITING Published online November 21, 2014; DOI: 10.3171/2014.10.JNS132159.

DISCLOSURE The authors report no conflict of interest concerning the materials or methods used in this study or the findings specified in this paper. 
most of the angiogenesis inhibitors used to treat cancer achieve their effect by blocking VEGF. ${ }^{21}$ Bevacizumab, a function-blocking monoclonal antibody against human VEGF-A, is now approved for the treatment of GBM. In preliminary studies, anti-VEGF agents prolonged the progression-free survival of GBM patients. In addition, the antipermeability effects of anti-VEGF agents improve tumor imaging and the quality of life for GBM patients by decreasing their dependence on corticosteroids. However, the response to anti-VEGF therapy is transient and does not increase overall survival times. ${ }^{7,11}$ Two recent independent randomized Phase III trials of bevacizumab in patients with newly diagnosed GBM showed that although first-line use of the drug prolonged progression-free survival by 3-4 months, the difference in the duration of the overall survival times between bevacizumab-treated and placebo-treated patients was not significant. ${ }^{5,12}$ Although bevacizumab was of limited benefit for the GBM patients as a whole, some exhibited a striking response and lived substantially longer. These exceptions highlight the usefulness of finding biomarkers that predict treatment response.

It has been demonstrated that GBM stem-like cells could give rise to tumor endothelium in vitro and in vivo. ${ }^{19,22,23}$ Blocking VEGF inhibits the maturation of tumor endothelial progenitors into endothelium but not the differentiation of CD133-positive cells into endothelial progenitors. Although this finding suggests that mesenchymal transition might be a mechanism that underlies the resistance to antiangiogenic treatment, ${ }^{23}$ no simple method is currently available for differentiating between tumor-derived and reactive microvascular proliferation cells and normal cells.

We attempted to develop a method for detecting the mesenchymal transition of tumor cells via stem-like cells. We also looked for a novel biomarker that would help identify poor responders to bevacizumab therapy. We first used immunostaining for p53 and isocitrate dehydrogenase 1 (IDH1) as a selection marker to identify tumor cells in tumor samples from the 61 patients with GBM. Then we focused on microvascular proliferation cells strongly positive for p53 and/or mutated IDH1 and determined the frequency and distribution of mesenchymal transition. To exclude the possibility of false-positive p53 immunostaining in tissue without the TP53 mutation in microvascular proliferation cells, we used a combination of laser microdissection and DNA sequence analysis.

\section{Methods \\ Sample Collection}

This study was approved by the Ethics Committee of the University of Miyazaki Hospital, Miyazaki, Japan; informed consent for the use of resected tissues was obtained from the 61 patients and their families. The tissue samples were obtained from GBM tumors resected at the Department of Neurosurgery, University of Miyazaki Hospital, during August 2005-December 2011. Gliosarcomas were excluded from analysis. Two or more pathologists examined all GBM tissue sections according to WHO criteria. ${ }^{16}$

We prepared slides of tissue from 2-5 sites per patient and evaluated the immunohistochemical expression of p53. Nuclear staining for p53 was scored semiquantitatively on the most prominently stained area of the slides. Cases with more than $10 \%$ p53-positive cells were regarded as positive and those with less than $10 \%$ as negative..$^{14}$ Cells with a p53-positive microvascular proliferation rate greater than $50 \%$ were selected for further study.

Genomic DNA was extracted from frozen samples of these resected tumors. We prescreened for the p53 mutation by direct DNA sequencing.

We also evaluated the immunohistochemical expression of IDH1. Strong cytoplasmic staining of tumor cells for mIDH1R132H was scored as positive; neither weak diffuse staining nor staining of macrophages was scored as positive. ${ }^{3}$

\section{Polymerase Chain Reaction and Direct DNA Sequencing for Prescreening of the Original Tumor}

Genomic DNA was isolated from frozen samples of the original tumor by using the QIAamp DNA Mini Kit (QIAGEN). To prescreen the samples for mutations in exons 4-9 of the p53 gene, we performed polymerase chain reactions (PCRs). ${ }^{18,24,26}$ Exon 5 was screened in 2 fragments (5a and $5 b$ ). The PCR primers for the amplification of p53 exons 4-9 were as follows: exon 4, 5'-ACTGCTCTTTTCACCCATCTAC-3' (sense) and 5'-TCATGGAAGCCAGCCCCTCAG-3' (antisense); exon 5a, 5'-TTATCTGTTCACTTGTGCCC-3' (sense) and 5'-TCATGTGCTGTGACTGCTTG-3' (antisense); exon 5b, 5'-TTCCACACCCCCGCCCGGCA-3' (sense) and 5'-ACCCTGGGCAACCAGCCCTG-3' (antisense); exon 6, 5'-AGACGACAGGGCTGGTTGCC-3' (sense) and 5'-TTAACCCCTCCTCCCAGAGA-3' (antisense); exon 7, 5'-ACTGGCCTCATCTTGGGCCT-3' (sense) and 5'-TGTGCAGGGTGGCAAGTGGC-3' (antisense); exon 8, 5'-TAAATGGGACAGGTAGGACC-3' (sense) and 5'-TCCACCGCTTCTTGTCCTGC-3' (antisense); exon 9, 5'-CCTATCCTGAGTAGTGGTAA-3' (sense) and 5'-CCAAGACTTAGTACCTGAAG-3' (antisense).

PCR assays were performed in a total reaction volume of $20 \mu \mathrm{l}$ containing $1 \mu \mathrm{l}$ of genomic DNA, $2 \mu \mathrm{l}$ of 10X Ex Taq Buffer (TaKaRa), $1.6 \mu$ l of dNTP mixture (TaKaRa), $0.2 \mu \mathrm{l}$ of Ex Taq (TaKaRa), $2.5 \mu \mathrm{l}$ of $5 \mu \mathrm{M}$ of each primer, and $10.2 \mu \mathrm{l}$ of distilled water. PCR amplification was performed in a GeneAmp PCR System 9700 (Applied Biosystems). Thermal cycling conditions were as follows: initial denaturation $\left(94^{\circ} \mathrm{C}\right)$ for 5 minutes, 35 cycles of denaturation $\left(94^{\circ} \mathrm{C}\right)$ for 50 seconds, annealing $\left(55^{\circ} \mathrm{C}\right.$ for exons $4,5 \mathrm{a}$, and 9 , and $60^{\circ} \mathrm{C}$ for exons $5 \mathrm{~b}, 6,7$, and 8 ) for 60 seconds, and extension $\left(72^{\circ} \mathrm{C}\right)$ for $70 \mathrm{sec}-$ onds. The PCR products were separated by electrophoresis in $2 \%$ agarose gels, and the target band was excised from the gel. The DNA fragments were extracted from the gel slice by using the QIAquick Gel Extraction Kit (QIAGEN). Each product was submitted for direct sequencing on an ABI PRISM 310 Genetic Analyzer (Applied Biosystems). The sequencing reactions were performed by using the Big Dye Terminator version 1.1 Cycle Sequencing Kit (Applied Biosystems) under the following conditions: initial denaturation $\left(96^{\circ} \mathrm{C}\right)$ for 1 minute, 25 cycles of denaturation $\left(96^{\circ} \mathrm{C}\right)$ for 10 seconds, annealing $\left(56^{\circ} \mathrm{C}\right)$ for 5 
seconds, and extension $\left(60^{\circ} \mathrm{C}\right)$ for 4 minutes. Sequences were analyzed with Sequence Scanner Software version 1.0 (Applied Biosystems).

\section{Collection of Tumor Vascular Cells}

Laser microdissection is useful for isolating and collecting a small number of cells from a specific site. Although it enables isolation of small cell colonies or single cells from tissues for genetic analysis, ${ }^{9,20}$ because coverslips cannot be applied, resolution is low. We collected tumor vascular cells by using laser microdissection and found it especially difficult to distinguish between vascular cells and glial cell components on slides immunostained for p53. Therefore, we identified microvascular proliferation with a high rate of $\mathrm{p} 53$ positivity on conventional $\mathrm{p} 53$ immunostained slides and collected cells from the same microvascular proliferation area on laser microdissection slides stained with hematoxylin and eosin (H\&E).

To create the slides, we cut $2-\mu \mathrm{m}$-thick tissue specimens from formalin-fixed, paraffin-embedded tissue samples and subjected them to deparaffinization and staining with $\mathrm{H} \& \mathrm{E}$. We then identified p53-positive microvascular proliferation in the p53-immunostained samples and collected vascular cells from the same microvascular proliferation area on the laser microdissection slides. To confirm that the $\mathrm{p} 53$-positive microvascular proliferation cells manifested the TP53 mutation, we performed laser microdissection (see Fig. 3) and DNA sequencing analysis (see Fig. 4).

Laser microdissection of the tumors was performed by using the laser microbeam technique and the PALM MicroBeam system (ZEISS). We collected approximately $100-150$ cells, taking care to avoid contamination with surrounding glial cell components when isolating the vascular cells. As a negative control, vascular cells demonstrating p53-negative microvascular proliferation were collected from the same case.

\section{PCR and Direct DNA Sequencing of Laser Microdissection Samples}

Genomic DNA was extracted from the microdissected cells with the QIAamp DNA Micro Kit (QIAGEN) according to the protocol for the extraction of genomic DNA from laser microdissection tissues. PCR assays were performed in a total reaction volume of $20 \mu \mathrm{l}$ containing $1 \mu \mathrm{l}$ of genomic DNA, $2 \mu \mathrm{l}$ of 10X Ex Taq Buffer (TaKaRa), $1.6 \mu \mathrm{l}$ of dNTP mixture (TaKaRa), $0.08 \mu \mathrm{l}$ of Ex Taq (Ta$\mathrm{KaRa}$ ), $0.8 \mu \mathrm{l}$ of $5 \mu \mathrm{M}$ of each primer, $2 \mu \mathrm{l}$ of 10X PCRx Enhancer Solution (Invitrogen), and $11.72 \mu \mathrm{l}$ of distilled water. Amplification was performed by initial denaturation $\left(94^{\circ} \mathrm{C}\right)$ for 12 minutes followed by 36 cycles of denaturation $\left(94^{\circ} \mathrm{C}\right)$ for 30 seconds, annealing $\left(61^{\circ} \mathrm{C}\right)$ for 40 seconds, and extension $\left(72^{\circ} \mathrm{C}\right)$ for 40 seconds. Purification of the PCR products and direct DNA sequencing were performed as described above, and p53 mutations were detected.

\section{Results}

The median age of the 61 patients ( 35 male, 26 female) was 63 years (Table 1). The clinical diagnosis was primary
TABLE 1. Baseline characteristics of samples from $61 \mathrm{GBM}$ patients and immunohistochemical detection of p53

\begin{tabular}{llll}
\hline & \multicolumn{3}{c}{ No. of Samples (\%) } \\
\cline { 2 - 4 } \multicolumn{1}{c}{ Variable } & $\begin{array}{c}\text { Primary } \\
\text { GBM }^{*}\end{array}$ & $\begin{array}{c}\text { Secondary } \\
\text { GBM }\end{array}$ & Total \\
\hline Tumor tissue samples & 58 & 3 & 61 \\
\hline Male sex (\%) & $34(58.6)$ & $1(33.3)$ & $35(57.4)$ \\
\hline Positive p53 immunostaining & $43(74.1)$ & $3(100)$ & $46(75.4)$ \\
\hline p53-positive rate of MVP $>50 \%$ & $3(5.2)$ & $0(0)$ & $3(4.9)$ \\
\hline MVP = microvascular proliferation. & & & \\
* Median patient age 63 years (range 10-85 years). \\
† Median patient age 55 years (range 52-62 years).
\end{tabular}

GBM in 58 patients and secondary GBM in 3 patients. The secondary GBMs were diagnosed as WHO Grade IV on the basis of histological criteria; they had been diagnosed as WHO Grade II or III at least 1 year before the most recent surgery. ${ }^{25}$

\section{p53 in GBM Specimens}

Of the initially selected GBM tumor samples with more than $10 \%$ positivity for p53 staining, 46 (75.4\%) were identified as p53-positive by immunostaining.

\section{p53 in Microvascular Proliferation Cells}

We identified 3 tumors in which more than $50 \%$ of the microvascular proliferation cells were p53-positive; p53positive microvascular proliferation areas tended to be clustered (Fig. 1 upper). Of note, areas of p53-negative microvascular proliferation were present in the same tumor samples (Fig. 1 lower). This finding suggests that mesenchymal transition can occur heterogeneously in the same tumor and confirms the heterogeneity of GBM.

To exclude p53-wild-type tumors, we performed DNA sequencing of the original specimens from these $3 \mathrm{tu}-$ mors. All tumor samples demonstrated point mutations of TP53 (Table 2). Specimens from Patients 1 and 2 contained a hotspot mutation (R175H) and that from Patient 3 contained a nonhotspot mutation (S260A). Immunohistological examination that used antibodies against glial fibrillary acidic protein, epidermal growth factor receptor, and low-/high-molecular-weight cytokeratin showed that the staining pattern was identical in p53-positive and p53-negative microvascular proliferation areas and that this pattern differed completely from that of the surrounding original tumor cells (Fig. 2). This observation suggests that the p53-positive tumor microvascular proliferation cells were not cells that had invaded from the original tumor but were the result of a phenotypic change of the tumor cells.

Results of laser microdissection and DNA sequencing analysis performed to show that the p53-positive microvascular proliferation cells manifested the TP53 mutation are shown in Figures 3 and 4, respectively. All 3 tumors with p53-positive microvascular proliferation cells revealed p53 mutations identical to those observed in the original tumor cells. However, p53-negative microvascular proliferation cells in adjacent areas retained the wild- 


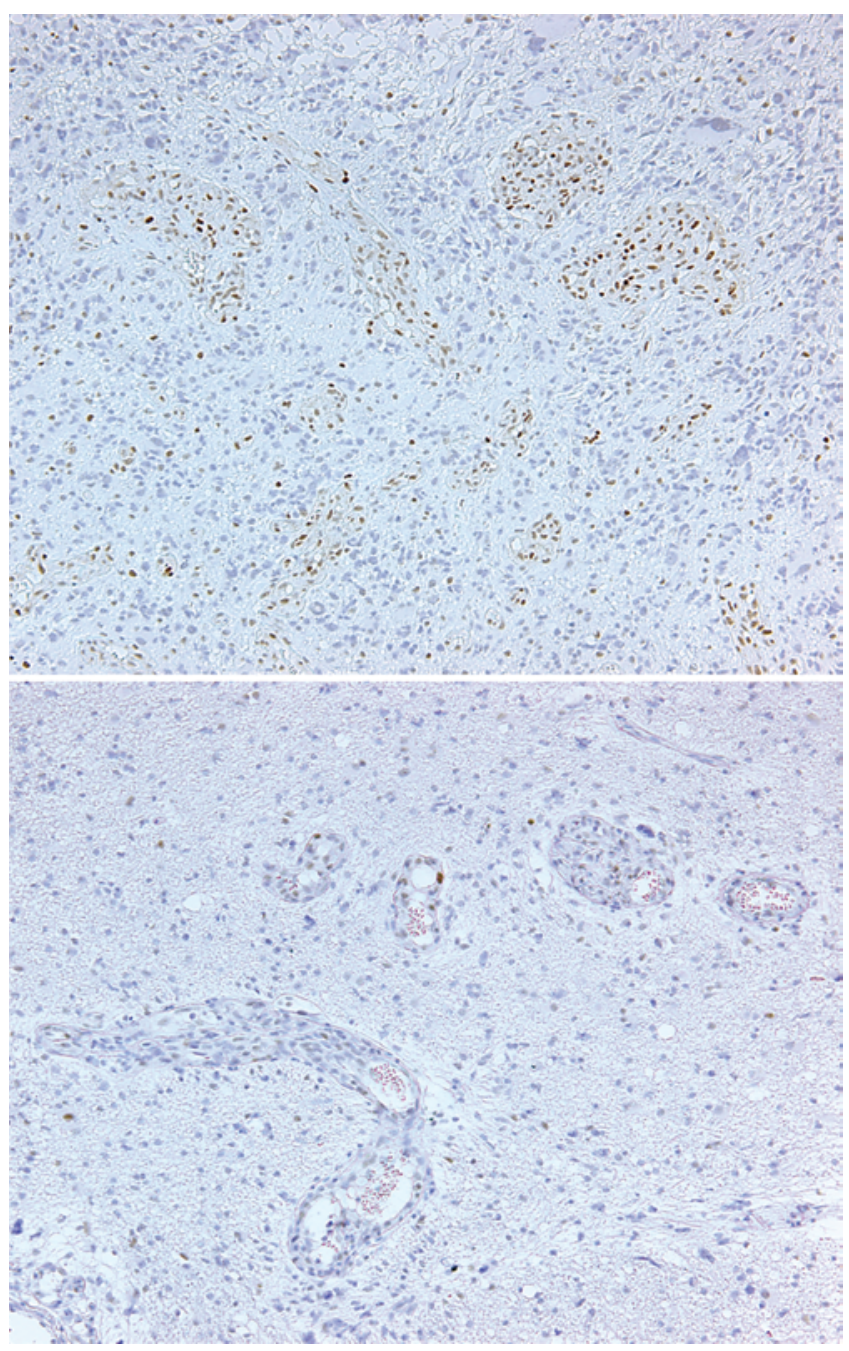

FIG. 1. Upper: Clustered p53-positive microvascular proliferation in a tumor sample. Lower: p53-negative microvascular proliferation in the same sample. Original magnification $\times 10$.

type p53 allele (Table 2). This finding confirms that some microvascular proliferation cells were derived from tumor cells via mesenchymal transition and that they formed clusters within the tumor tissue.

\section{Mutated IDH1 in Microvascular Proliferation Cells}

Because the mIDH1R132R antibody is specific and recognizes the IDH1R132H mutation, ${ }^{3,4}$ we did not verify the mutation of IDH1 by DNA sequencing of samples obtained by laser microdissection. As expected, most primary GBMs did not exhibit IDH1 staining. Only 3 (4.9\%) of

TABLE 2. Results of direct DNA sequencing of primary GBM tissue positive for microvascular proliferation

\begin{tabular}{ccc}
\hline Case No. & Mutation & Site (frozen tissue) \\
\hline 1 & R175H & CGC $>$ CAC \\
\hline 2 & R175H & CGC $>$ CAC \\
\hline 3 & S260A & TCC $>$ GCC \\
\hline
\end{tabular}

the 61 GBMs ( 2 primary and 1 secondary) showed positive staining for IDH1 antibody (Table 3), and we did not detect strong positive staining of microvascular proliferation cells for mutated IDH1 in these 3 tumors. This finding suggests that because of the low frequency of IDH1 mutations, IDH1 is not a suitable marker for the detection of microvascular proliferation anomalies in GBMs.

\section{Discussion}

Disease progression during treatment with VEGF inhibitors is attributable to multiple interacting mechanisms. Such mechanisms include compensatory actions of angiogenic growth factors that are not blocked by VEGF inhibitors, blood flow alterations caused by tumor vessel pruning and normalization, co-opting of normal peritumoral blood vessels, exaggeration of intratumoral hypoxia, activation of pathways that favor epithelial-mesenchymal transition, promotion of tumor invasiveness, suppression of the immune system, and induction of tolerance and activation of cancer stem cells. $1,6,8,15$

Among these complex mechanisms, mesenchymal transition via glioma stem-like cells has drawn attention. Blocking VEGF or silencing VEGF2 inhibits only the maturation of tumor endothelial progenitors into epithelium, not the differentiation of CD133-positive cells into endothelial progenitors. To block the transition into endothelial progenitors, the notch-1 signal must be inhibited. ${ }^{23}$ However, the frequency of this inhibition remains to be demonstrated in clinical tumor samples.

We attempted to establish a method for identifying the putative mesenchymal transition of tumor cells via glioma stem-like cells. Kulla et al. ${ }^{13}$ used laser microdissection to select GBM specimens with significant p53 accumulation according to immunohistochemical staining and to isolate proliferated glomeruloid stromal vessels. They reported that DNA sequence analysis failed to demonstrate TP53 mutations and concluded that microvascular proliferation originated from the tumor stroma.

On the basis of experimental evidence suggesting that GBM cells have the potential to transdifferentiate into endothelial cells,,${ }^{19,23}$ we analyzed microvascular proliferation in GBMs. To condense the mesenchymal transition in microvascular proliferation, we applied a 2-step screening method. We first set a cutoff value of $10 \%$ immunopositivity for $\mathrm{p} 53$. Consequently, the positive ratio increased to $70 \%$ in our 61 GBM samples. This value is higher than that reported by Ohgaki et al.:18 in their population-based study, $31 \%$ of GBMs manifested the TP53 mutation. In the first screening, immunopositive staining for p53 did not necessarily confirm the TP53 mutation. Therefore, we selected tumors with possible TP53 mutations and then focused on the p53-positive cells in the area of microvas-

TABLE 3. Immunohistochemical expression of IDH1

\begin{tabular}{clr}
\hline & \multicolumn{2}{c}{ No. of Samples (\%) } \\
\cline { 2 - 3 } IDH1 Immunohistochemistry & Positive & Negative \\
\hline Primary GBM $(n=58)$ & $2(3.4)$ & $56(96.6)$ \\
\hline Secondary GBM $(n=3)$ & $1(33.3)$ & $2(66.6)$ \\
\hline Total $(n=61)$ & $3(4.9)$ & $58(95.1)$ \\
\hline
\end{tabular}




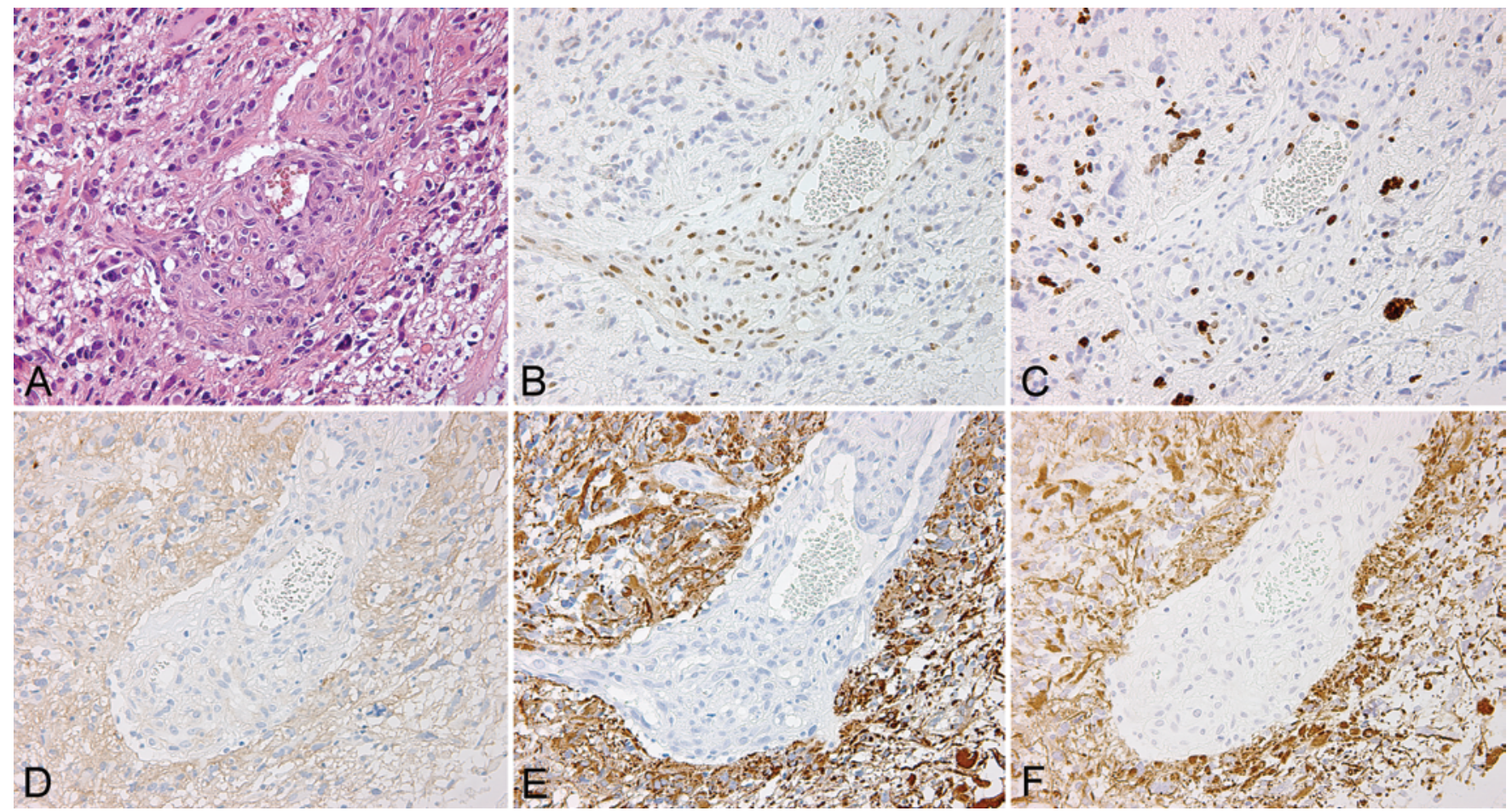

FIG. 2. Pathological findings in p53-positive microvascular proliferation cells. A: H \& E: microvascular proliferation exhibiting a glomerular structure. B: p53: Almost all cells within the microvascular proliferation area showing positivity. C: MIB-1: The MIB-1 index in this case was 33\%. D: Epidermal growth factor receptor. E: Glial fibrillary acidic protein. F: Low-/high-molecular-weight cytokeratin: positive expression in the glial cell component. The microvascular proliferation was negative for these markers. Original magnification $\times 20$.

cular proliferation. After careful inspection of the positive samples in the second screening, we identified 3 GBM samples that contained areas with a high positive ratio (> $50 \%$ ) for p53. All 3 GBMs were clinically diagnosed as primary glioblastomas. We confirmed the TP53 mutation of microvascular proliferation cells by DNA sequencing analysis and found hotspot mutations $(\mathrm{R} 175 \mathrm{H})$ in 2 and a nonhot spot mutation (S260A) in 1 microvascular proliferation sample. This observation is consistent with that of Ohgaki et al.. ${ }^{18}$ who reported TP53 mutations in secondary glioblastomas; $57 \%$ were in hotspot codons 248 and 273, and in primary glioblastomas, the mutations were more equally distributed.

We did not detect microvascular proliferation cells positive for IDH1 immunostaining in any of the GBM samples. Our series included only 3 secondary GBMs in which the IDH1 mutation has been reported to be more frequent. ${ }^{20}$ Therefore, we think that IDH1 immunostaining is not a good candidate for mesenchymal transition screening, at least in primary GBMs.

We detected clusters of mesenchymal transdifferentiated microvascular proliferation in some areas; they coex-

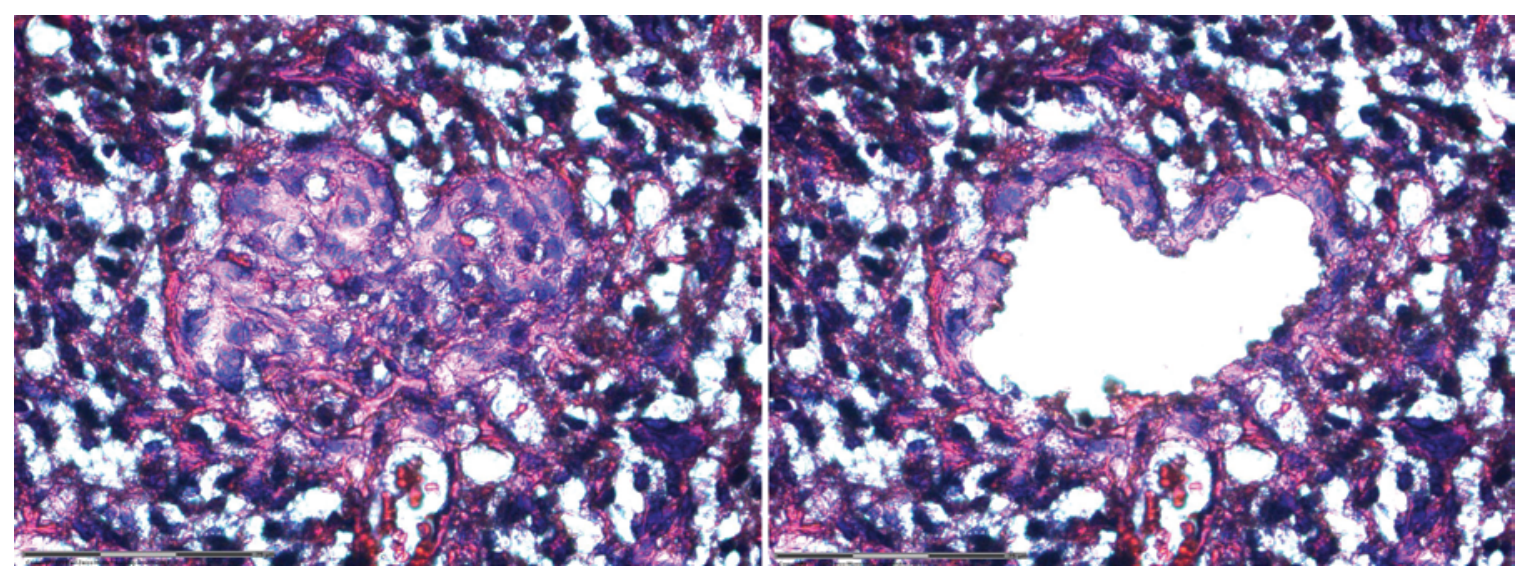

FIG. 3. Microvascular proliferation on H \& E-stained laser microdissection slides. Left: Before laser microdissection. Right: After laser microdissection. Original magnification $\times 40$. 

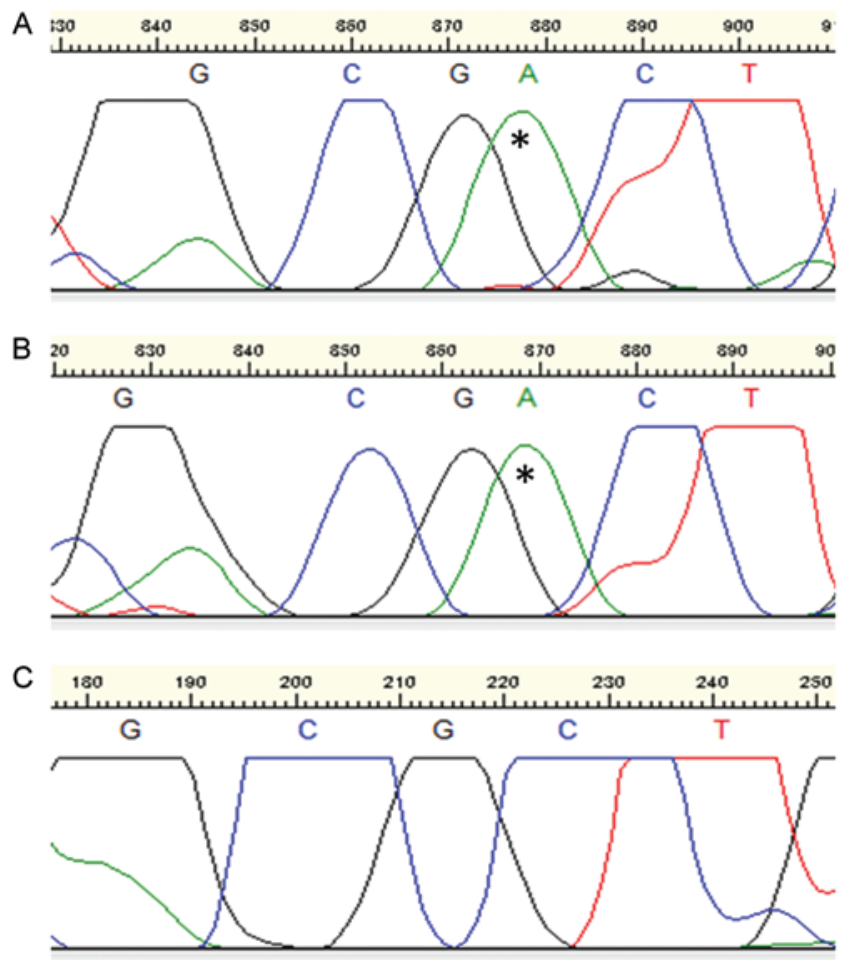

FIG. 4. Direct DNA sequencing results for one case. A: R175H in the sequence from frozen resected tumor tissue samples. B: Sequence of p53-positive-immunostained vascular cells collected by laser microdissection showing R175H (also found in the frozen sample). C: Sequence of p53-negative-immunostained vascular cells collected by laser microdissection; no mutation is observed. Asterisk indicates R175H.

isted with microvascular proliferation cells derived from normal stromal cells. This finding may have rendered the detection of TP53 mutations on laser microdissection samples difficult and might explain why Kulla et al. ${ }^{13}$ failed to identify these mutations.

In our series, the rate of clustered mesenchymal transition from the tumor to microvascular proliferation was $4.9 \%$ ( 3 of $61 \mathrm{GBMs}$ ), although the TP53 mutation and IDHI were not manifested in most of the GBMs. This rate was obtained by screening for the immunopositivity of microvascular proliferation cells under stringent conditions $(>50 \%$ ). It is possible that a decrease in cutoff ratio to, for example, $30 \%$ would lead to a possible increased rate of mesenchymal transition. However, direct DNA sequence analysis might fail to detect the small number of positive mutated microvascular proliferation cells. With good markers, this ratio may increase. Our findings emphasize the need for a better understanding of the mechanisms by which mesenchymal transition facilitates the escape of tumor cells from the effects of antiangiogenic agents.

\section{Conclusions}

We have shown that some clustered microvascular proliferation cells in GBMs could be derived from mesenchymal transition. If we could find other useful markers, this phenomenon might be demonstrated as an infrequent event in GBMs.

\section{Acknowledgment}

We thank Ayumi Nagatomo for technical assistance.

\section{References}

1. Bergers G, Hanahan D: Modes of resistance to anti-angiogenic therapy. Nat Rev Cancer 8:592-603, 2008

2. Brat DJ, Van Meir EG: Glomeruloid microvascular proliferation orchestrated by VPF/VEGF: a new world of angiogenesis research. Am J Pathol 158:789-796, 2001

3. Capper D, Weissert S, Balss J, Habel A, Meyer J, Jäger D, et al: Characterization of R132H mutation-specific IDH1 antibody binding in brain tumors. Brain Pathol 20:245-254, 2010

4. Capper D, Zentgraf H, Balss J, Hartmann C, von Deimling A: Monoclonal antibody specific for IDH1 R132H mutation. Acta Neuropathol 118:599-601, 2009

5. Chinot OL, Wick W, Mason W, Henriksson R, Saran F, Nishikawa R, et al: Bevacizumab plus radiotherapy-temozolomide for newly diagnosed glioblastoma. N Engl J Med 370:709-722, 2014

6. De Bock K, Mazzone M, Carmeliet P: Antiangiogenic therapy, hypoxia, and metastasis: risky liaisons, or not? Nat Rev Clin Oncol 8:393-404, 2011

7. de Groot JF, Mandel JJ: Update on anti-angiogenic treatment for malignant gliomas. Curr Oncol Rep 16:380, 2014

8. Ebos JM, Kerbel RS: Antiangiogenic therapy: impact on invasion, disease progression, and metastasis. Nat Rev Clin Oncol 8:210-221, 2011

9. Emmert-Buck MR, Bonner RF, Smith PD, Chuaqui RF, Zhuang Z, Goldstein SR, et al: Laser capture microdissection. Science 274:998-1001, 1996

10. Ferrara N, Kerbel RS: Angiogenesis as a therapeutic target. Nature 438:967-974, 2005

11. Gerstner ER, Batchelor TT: Antiangiogenic therapy for glioblastoma. Cancer J 18:45-50, 2012

12. Gilbert MR, Dignam JJ, Armstrong TS, Wefel JS, Blumenthal DT, Vogelbaum MA, et al: A randomized trial of bevacizumab for newly diagnosed glioblastoma. N Engl J Med 370:699-708, 2014

13. Kulla A, Burkhardt K, Meyer-Puttlitz B, Teesalu T, Asser T, Wiestler OD, et al: Analysis of the TP53 gene in lasermicrodissected glioblastoma vasculature. Acta Neuropathol 105:328-332, 2003

14. Levidou G, El-Habr E, Saetta AA, Bamias C, Katsouyanni $\mathrm{K}$, Patsouris E, et al: P53 immunoexpression as a prognostic marker for human astrocytomas: a meta-analysis and review of the literature. J Neurooncol 100:363-371, 2010 (Erratum in J Neurooncol 100:373, 2010)

15. Loges S, Schmidt T, Carmeliet P: Mechanisms of resistance to anti-angiogenic therapy and development of thirdgeneration anti-angiogenic drug candidates. Genes Cancer 1:12-25, 2010

16. Louis DN, Ohgaki H, Wiestler OD, Cavenee WK, Burger PC, Jouvet A, et al: The 2007 WHO classification of tumours of the central nervous system. Acta Neuropathol 114:97-109, 2007

17. Machein MR, Plate KH: VEGF in brain tumors. J Neurooncol 50:109-120, 2000

18. Ohgaki H, Dessen P, Jourde B, Horstmann S, Nishikawa T, Di Patre PL, et al: Genetic pathways to glioblastoma: a population-based study. Cancer Res 64:6892-6899, 2004

19. Ricci-Vitiani L, Pallini R, Biffoni M, Todaro M, Invernici G, Cenci T, et al: Tumour vascularization via endothelial differentiation of glioblastoma stem-like cells. Nature 468:824828,2010

20. Schütze K, Lahr G: Identification of expressed genes by laser-mediated manipulation of single cells. Nat Biotechnol 16:737-742, 1998 
21. Sennino B, McDonald DM: Controlling escape from angiogenesis inhibitors. Nat Rev Cancer 12:699-709, 2012

22. Soda Y, Marumoto T, Friedmann-Morvinski D, Soda M, Liu F, Michiue H, et al: Transdifferentiation of glioblastoma cells into vascular endothelial cells. Proc Natl Acad Sci U S A 108:4274-4280, 2011

23. Wang R, Chadalavada K, Wilshire J, Kowalik U, Hovinga $\mathrm{KE}$, Geber A, et al: Glioblastoma stem-like cells give rise to tumour endothelium. Nature 468:829-833, 2010

24. Watanabe K, Tachibana O, Sata K, Yonekawa Y, Kleihues P, Ohgaki H: Overexpression of the EGF receptor and p53 mutations are mutually exclusive in the evolution of primary and secondary glioblastomas. Brain Pathol 6:217-224, 1996

25. Yan H, Parsons DW, Jin G, McLendon R, Rasheed BA, Yuan W, et al: IDH1 and IDH2 mutations in gliomas. N Engl J Med 360:765-773, 2009

26. Zariwala M, Schmid S, Pfaltz M, Ohgaki H, Kleihues P, Schäfer R: p53 gene mutations in oropharyngeal carcinomas: a comparison of solitary and multiple primary tumours and lymph-node metastases. Int J Cancer 56:807-811, 1994

\section{Author Contributions}

Conception and design: Kawasoe, Takeshima. Acquisition of data: Kawasoe, Yamashita, Mizuguchi, Fukushima, Yokogami, Yamasaki. Analysis and interpretation of data: Kawasoe.

Reviewed submitted version of manuscript: Kawasoe, Takeshima. Approved the final version of the manuscript on behalf of all authors: Kawasoe.

\section{Correspondence}

Takuma Kawasoe, Department of Neurosurgery, Division of Clinical Neuroscience, Faculty of Medicine, University of Miyazaki, 5200 Kihara, Kiyotake, Miyazaki, 889-1692, Japan. email: tkawasoe@email.jp. 